\title{
Demographic Characteristics of Diabetic Neuropathy Patients Attended at a Tertiary Care Hospital in Dhaka City
}

\author{
Mohammad Mashudur Rahman*1, Abu Nasir Rizvi ${ }^{2}$, Mohammad Nazim Uddin ${ }^{3}$, \\ Rashida Akter Khanam ${ }^{4}$, Muhammad Abdul Momen Khan ${ }^{5}$, Shafia Khanam ${ }^{6}$
}

\begin{abstract}
Introduction: Diabetic neuropathy is one of the early complications of diabetes mellitus patients which is very difficult to face in the daily living activities. The purpose of the present study was to see the demographic characteristics of diabetic neuropathy patients. Metarials \& Methods: This descriptive type of cross-sectional study was conducted in the Department of Neurology including Neuropathy Clinic and in collaboration with department of Endocrinology at Banghabandhu Sheikh Mujib Medical University, Dhaka from January 2012 to December 2013 for a period of two (2) years. Adult diabetic patients presented with neuropathic pain with symmetrical involvement of distal limbs from indoor and outpatient department of Neurology including Neuropathy clinic as well as indoor and outpatient department of Endocrinology, BSMMU were enrolled in the study population. Data was collected by face to face interview. Information was collected by taking medical history and clinical examinations and subsequent laboratory investigations. Results: A total number of 102 cases were recruited for this study who were clinically diagnosed as painful diabetic polyneuropathy. Female was predominant than male 55(53.9\%) cases and $47(46.1 \%)$ cases respectively. The male and female ratio was 1:1.2. Majority were in the age group of more than 55 years which was $55(53.9 \%)$ cases. The mean age with $S D$ of the study population was $52.79 \pm 9.42$ years. Among 102 patients type II DM was predominate than type I patients which were 95(92.2\%) cases and $8(7.8 \%)$ cases respectively. The mean duration of DM with $S D$ was $6.51 \pm 3.6$ years. However the mean duration of neuropathic pain was $1.68 \pm 1.155$ years. Conclusion: In conclusion majority of the diabetic neuropathy patients are female suffering from type II DM in the middle age.
\end{abstract}

Keywords: Diabetic Neuropathy, Demographic Characteristics, Type II DM.

Number of Tables: 04; Number of References: 18; Number of Correspondences: 06

*1. Corresponding Author: Dr. Mohammad Mashudur Rahman

Assistant Professor

Department of Neurology

Sheikh Sayera Khatun Medical College, Gopalgonj, Bangladesh.

Email: masudatmon@gmail.com

2. Prof. Dr. Abu Nasir Rizvi

Professor

Department of Neurology

Bangabandhu Sheikh Mujib Medical University, Dhaka, Bangladesh.

3. Dr. Mohammad Nazim Uddin

Assistant Professor

Department of ENT

Sheikh Sayera Khatun Medical College, Gopalgoinj, Bangladesh.

4. Dr. Rashida Akter Khanam

Assistant Professor

Department of Microbiology

Shaheed Suhrawardy Medical College, Dhaka, Bangladesh.

\section{Dr. Muhammad Abdul Momen Khan}

Assistant Professor

Department of Interventional Neurology

National Institute of Neurosciences \& Hospital, Dhaka, Bangladesh.

6. Dr. Shafia Khanam

Medical Officer

National Institute of Mental health \& Hospital, Dhaka, Bangladesh.

\section{Introduction}

Painful diabetic polyneuropathy is a common manifestation of diabetes mellitus ${ }^{1}$. Painful diabetic polyneuropathy significantly affect on the quality of life, sleep, mood, mobility, ability to motor activities and social behaviors of patients ${ }^{2}$. High prevalence of diabetes and consequently painful neuropathy limits the daily activities of the patients ${ }^{3}$.

Diabetic neuropathy is one of the most underestimated, very common and early among the complications of diabetes mellitus (DM) ${ }^{4}$. The most common type of neuropathy in DM is diabetic peripheral neuropathy (DPN), with up to $50 \%$ of patients experiencing some degree of painful symptoms and $10 \%$ to $20 \%$ having symptoms severe enough to warrant treatment ${ }^{5}$. A classic population-based study found some degree of neuropathy in $66.0 \%$ of patients with DM. Among those $54.0 \%$ with type 1 and $45.0 \%$ with type 2 DM had DPN. This study has also shown that $15 \%$ of DPN in type 1 and $13 \%$ in type 2 DM are symptomatic ${ }^{6}$. Prevalence of neuropathic symptoms increases with the duration of diabetes and quality of glycemic control ${ }^{7}$. Although $7.5 \%$ diabetics, at the time of diagnosis, can have neuropathy, the incidence increases to about $50 \%$ after 20 to 25 years of diabetic life $^{3}$. Up to $25 \%$ of individuals with 
diabetes develop painful diabetic neuropathy, more than 14 million people in the United States with diabetes mellitus, nearly a quarter, suffer from painful diabetic neuropathy ${ }^{5}$. In this context this present study was undertaken to see the demographic characteristics of diabetic neuropathy patients.

\section{Materials and Methods}

This was a descriptive type of cross-sectional study conducted from January 2012 to December 2013 for a period of two (2) years. This study was carried out in the Department of Neurology including Neuropathy Clinic andin collaboration with Department of Endocrinology at Banghabandhu Sheikh Mujib Medical University, Dhaka. Adult diabetic patients presented with neuropathic pain with symmetrical involvement of distal limbs from indoor and outpatient department of Neurology including Neuropathy clinic as well as indoor and outpatient department of Endocrinology, BSMMU were enrolled in the study population. Patients with the age group of below 18 and above 65 years, having the history of drug hypersensitivity reaction, impaired hepatic and renal function, pregnant women and in lactation were excluded from this study. All respondents were selected purposively and convenientlyfrom theaforementioned study places. Data collection sheet was used to collect patient's information. Data was collected by face to face interview. Information was collected by taking medical history and clinical examinations and subsequent laboratory investigations. Data was analyzed by computer with the help of SPSS version 21.0 software package. All data was recorded systematically in a preformed data collection sheet and expressed the quantitative variables as mean $\pm \mathrm{SD}$. It was analyzed for categorical variables by using chi-squared test and for continuous variable t-test used. For all statistical tests, we considered $\mathrm{p}$ value $<0.05$ as statistically significant. Prior to the commencement of this study, the research protocol was approved by the Institutional Review Board (IRB) of BSMMU, Dhaka.

\section{Results}

A total number of 102 cases were recruited for this study who were clinically diagnosed as painful diabetic polyneuropathy. In this study female was predominant than male which was $55(53.9 \%)$ cases and $47(46.1 \%)$ cases respectively. The male and female ratio was 1:1.2 (Table I).

Table-I: Distribution of the Respondents by Gender $(n=102)$.

\begin{tabular}{ccc}
\hline Gender & Frequency & Percentage \\
\hline Female & 55 & 53.9 \\
Male & 47 & 46.1 \\
\hline Total & $\mathbf{1 0 2}$ & $\mathbf{1 0 0 . 0}$ \\
\hline
\end{tabular}

Among 102 patients majority were in the age group of more than 55 years which was $55(53.9 \%)$ cases followed by 45 to 54 years, 35 to 44 years and 35 to 44 years which were $30(29.4 \%)$ cases, $12(11.8 \%)$ cases and $5(4.9 \%)$ cases respectively. The mean age with $\mathrm{SD}$ of the study population was $52.79 \pm 9.42$ years with the age range of minimum 25 years and the maximum was 65 years (Table II).

Table-II: Distribution of the Respondents by Age Groups $(\mathrm{n}=102)$.

\begin{tabular}{lcc}
\hline Age Group & Frequency & Percentage \\
\hline 25 to 34 Years & 5 & 4.9 \\
35 to 44 Years & 12 & 11.8 \\
45 to 54 Years & 30 & 29.4 \\
More than 55Years & 55 & 53.9 \\
\hline Total & $\mathbf{1 0 2}$ & $\mathbf{1 0 0 . 0}$ \\
\hline Mean $( \pm$ SD) & $52.79 \pm 9.42$ (Range 25-65) \\
\hline
\end{tabular}

Among 102 patients type II DM was predominate than type I patients which were $95(92.2 \%)$ cases and $8(7.8 \%)$ cases respectively. The ratio of type I and type II DM was 1:11.7 (Table III).

Table-III: Distribution of the Respondents by Type of DM $(\mathrm{n}=102)$.

\begin{tabular}{ccc}
\hline Type of DM & Frequency & Percentage \\
\hline Type I & 8 & 7.8 \\
Type II & 94 & 92.2 \\
\hline Total & $\mathbf{1 0 2}$ & $\mathbf{1 0 0 . 0}$ \\
\hline
\end{tabular}

The mean duration of DM with SD was $6.51 \pm 3.6$ years. However the mean duration of neuropathic pain was $1.68 \pm 1.155$ years (Table IV).

Table-IV: Mean Duration of DM and Neuropathic Pain among the Study Population.

\begin{tabular}{lc}
\hline Variables & Mean \pm SD \\
\hline Duration of DM (yrs) & $6.51 \pm 3.6$ \\
Duration of Neuropathic Pain (yrs) & $1.68 \pm 1.155$ \\
\hline
\end{tabular}

\section{Discussion}

Painful diabetic polyneuropathy significantly affect on the quality of life, sleep, mood, mobility, ability to motor activities and social behaviors of patients ${ }^{8}$. High prevalence of diabetes and consequently painful neuropathy limits the daily activities of the patients. This cross-sectional study was conducted in the departments of neurology including neuropathy clinic as well as Department of Endocrinology, BSMMU, Dhaka. A total number of 102 diabetic neuropathy patients have been recruited for this study who are clinically diagnosed as painful diabetic polyneuropathy. In this study female was predominant than male which was $55(53.9 \%)$ cases and 47(46.1\%) cases respectively. The male and female ratio was $1: 1.2$. Thus it is very clear that diabetic neuropathy is more commonly occur in the female than male. Similarly Galer et $\mathrm{al}^{7}$ have found $50 \%$ male and their findings are comparable with the findings of the present study. In the PHN group female patients 
dominate over male patients which reflect the gender distribution in this age in the general population. In DPN males are relatively more frequently affected ${ }^{4}$.

Among 102 patients majority were in the age group of more than 55 years which was $55(53.9 \%)$ cases followed by 45 to 54 years, 35 to 44 years and 35 to 44 years which were $30(29.4 \%)$ cases, $12(11.8 \%)$ cases and $5(4.9 \%)$ cases respectively. The mean age with SD of the study population was $52.79 \pm 9.42$ years with the age range of minimum 25 years and the maximum was 65 years. Interestingly, age has no influence on sensory symptoms in both neuropathic entities. The fact that younger diabetic patients have slightly more intense neuropathic pain was unexpected. Again, the explanation might be the selection bias in specialized pain centers. Many younger patients with mild pain have been missed.

Painful diabetes neuropathy is common in type II diabetes mellitus. In this study among 102 patients type II DM was predominate than type I patients which were 95(92.2\%) cases and $8(7.8 \%)$ cases respectively. The ratio of type I and type II DM was 1:11.7. In a study conducted by Zeigler et $\mathrm{al}^{8}$ pain in the feet and legs occurred in $11.6 \%$ of insulin dependent diabetics and $32.1 \%$ of noninsulin dependent diabetics.

The typical DPN is a chronic, symmetrical, length-dependent sensorimotor polyneuropathy (DSPN) and is thought to be the most common variety 9 . It develops on or with a background of long standing hyperglycemia, associated metabolic derangements increased polyol flux, accumulation of advanced glycation end products, oxidative stress, and lipid alterations among other metabolic abnormalities and cardiovascular risk factors ${ }^{10-11}$. Alterations of microvessels, similar to those observed in diabetic retinopathy and nephropathy, appear to be associated with the pathologic alterations of nerves ${ }^{12}$. Total hyperglycemic exposure is perhaps the most important risk covariate ${ }^{13}$. This variety has been shown to be stabilized, perhaps even improved, by rigorous glycemic control. This polyneuropathy has been shown to be statistically associated with retinopathy and nephropathy ${ }^{14}$. Autonomic dysfunction and neuropathic pain may develop over time. The atypical DPNs are different from DSPN in several important features, i.e., onset, course, manifestations, associations, and perhaps putative mechanisms ${ }^{15}$. They appear to be intercurrent varieties, developing at any time during the course of a patient's diabetes ${ }^{16}$. Onset of symptoms may be acute, subacute, or chronic, but the course is usually monophasic or fluctuating over time. Pain and autonomic symptoms are typical feature ${ }^{17}$ and altered immunity has been suggested. Studies have suggested that impaired fasting glucose or impaired glucose tolerance (IGT) is more common in chronic idiopathic axonal polyneuropathy ${ }^{18}$.

\section{Conclusion}

Diabetic neuropathy is a permanent irreversible debilitating but preventable microvascular complication.
It produce a significant devastating effect on quality of life. Prevalence higher with increasing age and duration of diabetic life. Strict glycemic control improve quality of life.

\section{Conflict of Interests: None.}

\section{Acknowledgement}

Thanks and all praise to Almighty Allah, the beneficial, the merciful for providing us enough energy and patience to complete this article. Our special thanks and gratitude to Prof (Dr) Md. Rezaul Karim Khan, Professor and Ex chairman, Department of Neurology, Bangabandhu Sheikh Mujib Medical University, Dhaka, Bangladesh for providing instructions, encouragement and valuable advice from begaining of the study. We would like to express our sincere gratitude and gratefulness to all teachers, doctors and employee in the department of Neurology and Endocrinology, Bangabandhu Sheikh Mujib Medical University, Dhaka, Bangladesh for valuable suggestions and advices to complete this study.

\section{References}

1. Huizinga MM, Peltier A. Painful diabetic neuropathy: a management-centered review. Clinical Diabetes. 2007; 25(1): 6-15.

https://doi.org/10.2337/diaclin.25.1.6

2. Polydefkis M, Griffin JW, McArthur J. New insights into diabetic polyneuropathy. Jama. 2003; 290(10):1371-6. https://doi.org/10.1001/jama.290.10.1371

PMid:12966130

3. Schmader KE. Epidemiology and impact on quality of life of postherpetic neuralgia and painful diabetic neuropathy. The Clinical journal of pain. 2002; 18(6): 350-4.

https://doi.org/10.1097/00002508-200211000-00002

PMid:12441828

4. Argoff CE, Cole BE, Fishbain DA, Irving GA. Diabetic peripheral neuropathic pain: clinical and quality-of-life issues. In Mayo Clinic Proceedings. 2006; 81(4): S3-S11.

https://doi.org/10.1016/S0025-6196(11)61474-2

5. Barrett AM, Lucero MA, Le T, Robinson RL, Dworkin RH, Chappell AS. Epidemiology, public health burden, and treatment of diabetic peripheral neuropathic pain: a review. Pain medicine. 2007; 8(s2): S50-62.

https://doi.org/10.1111/j.1526-4637.2006.00179.x

PMid:17714116

6. Boulton AJ, Malik RA, Arezzo JC, Sosenko JM. Diabetic somatic neuropathies. Diabetes care. 2004; 27(6):1458-86.

https://doi.org/10.2337/diacare.27.6.1458

PMid:15161806 
7. Galer BS, Gianas A, Jensen MP. Painful diabetic polyneuropathy: epidemiology, pain description, and quality of life. Diabetes research and clinical practice. 2000; 47(2): 123-8.

https://doi.org/10.1016/S0168-8227(99)00112-6

8. Ziegler D, Nowak H, Kempler P, Vargha P, Low PA. Treatment of symptomatic diabetic polyneuropathy with the antioxidant $\alpha$-lipoic acid: a meta-analysis. Diabetic Medicine. 2004; 21(2):114-21.

https://doi.org/10.1111/j.1464-5491.2004.01109.x

PMid:14984445

9. Said G. Diabetic neuropathy - a review. Nature clinical practice Neurology. 2007; 3(6): 331-40.

https://doi.org/10.1038/ncpneuro0504

\section{PMid:17549059}

10. Tesfaye S, Boulton AJ, Dyck PJ, Freeman R, Horowitz M, Kempler P, et al. Diabetic neuropathies: update on definitions, diagnostic criteria, estimation of severity, and treatments. Diabetes care. 2010; 33(10): 2285-93.

https://doi.org/10.2337/dc10-1303

PMid:20876709 PMCid:PMC2945176

11. Vinik AI, Mehrabyan A. Diabetic neuropathies. Medical Clinics of North America. 2004 Jul 31; 88(4): 947-99.

https://doi.org/10.1016/j.mcna.2004.04.009

PMid:15308387

12. Dyck PJ, Davies JL, Clark VM, Litchy WJ, Dyck PJ, Klein CJ, et al. Modeling chronic glycemic exposure variables as correlates and predictors of microvascular complications of diabetes. Diabetes Care. 2006; 29(10): 2282-8.

https://doi.org/10.2337/dc06-0525

PMid:17003307

13. Singleton JR, Smith AG, Bromberg MB. Painful sensory polyneuropathy associated with impaired glucose tolerance. Muscle \& nerve. 2001; 24(9): 1225-8.

https://doi.org/10.1002/mus.1136

PMid:11494277
14. England JD, Gronseth GS, Franklin G, Miller RG, Asbury AK, Carter GT, et al. American Academy of Neurology, American Association of ElectrodiagnosticMedicine, American Academy of Physical Medicine and Rehabilitation. Distal symmetric polyneuropathy: a definition for clinical research: report of the American Academy of Neurology, the American Association of Electrodiagnostic Medicine, and the American Academy of Physical Medicine and Rehabilitation. Neurology. 2005; 64:199-207.

https://doi.org/10.1212/01.WNL.0000149522.32823.EA

PMid:15668414

15. Dyck PJ, Overland CJ, Low PA, Litchy WJ, Davies JL, Dyck PJ, et al. Signs and symptoms versus nerve conduction studies to diagnose diabetic sensorimotor polyneuropathy: CI vs. N Phys trial. Muscle Nerve. 2010; 42: $157-164$.

https://doi.org/10.1002/mus.21661

PMid:20658599 PMCid:PMC2956592

16. Treede RD, Jensen TS, Campbell JN, Cruccu G, Dostrovsky JO, Griffin JW, et al. Neuropathic pain: redefinition and a grading system for clinical and research purposes. Neurology. 2008; 70: 1630-1635.

https://doi.org/10.1212/01.wnl.0000282763.29778.59

\section{PMid:18003941}

17. Spallone V, Maiello MR, Morganti R, Mandica S, Frajese G. Usefulness of ambulatory blood pressure monitoring in predicting the presence of autonomic neuropathy in type I diabetic patients. J Hum Hypertens. 2007; 21: 381-386.

https://doi.org/10.1038/sj.jhh.1002162

PMid:17301823

18. Vinik AI, Ziegler D. Diabetic cardiovascular autonomic neuropathy. Circulation. 2007; 115: 387-397.

https://doi.org/10.1161/CIRCULATIONAHA.106.634949

PMid:17242296 